\title{
Evidence of Fertility Decline in Karachi
}

\author{
Zeba A. Sathar and Afifa Akhtar*
}

\section{INTRODUCTION}

From most accounts of demographic transition in other societies it is expected that fertility is more likely to undergo changes in urban areas and these differences in reproductive behaviour will permeate only at a later stage to rural areas. In the light of the persistently high rate of population growth in Pakistan, fertility levels have acquired acute importance. Growth rates have been found to be ever higher in the urban areas of Pakistan and are estimated to be over 4 percent per annum as compared to a growth rate of 3 percent for Pakistan as a whole. The higher urban rate of growth has been attributed both to lower mortality and higher marital fertility in urban areas in combination with substantial rural to urban migration.

Whereas in most societies, urban fertility is found to be lower than rural fertility (Alam and Casterline 1983) this was not the case for Pakistan. Earlier findings based on the Pakistan Fertility Survey 1975 and the Population Labour Force and Migration Survey $1979^{1}$ both found that urban marital fertility exceeded rural marital fertility whereas, the total fertility rate as an outcome of later marriage patterns urban areas, was slightly lower than in rural areas [Alam et al. (1983); Sathar (1979)] .

The Pakistan Contraceptive Prevalence Survey 1984 brings out some further details of interest; the total fertility rate of major urban areas was found to be much lower than that for the rural areas and the highest fertility was found in the areas classified as "other urban" (Population Welfare Division 1986). Thus, a pattern of transition can be speculated for the whole of Pakistan through fertility differentials depicted in Major Urban, Other Urban and Rural Areas, whereby fertility can be expected to rise (as in 'other urban' areas) before it ultimately falls (as in major urban areas). In the Pakistan Fertility Survey, however, marital fertility in major urban areas was not different from other urban areas and if marital fertility has declined in these areas it is likely to be a more recent change.

We intend to utilize data from the survey of "Metropolitan Women's Productive and Reproductive Choices" (1988) carried out by Zeba Sathar and Shahnaz

*The authors are respectively, Senior Research Demographer and Staff Demographer at the Pakistan Institute of Development Economics, Islamabad.

'Details of these Surveys available in: Population Planning Council of Pakistan (1976). Pakistan Fertility Survey: First Report. M. Irfan (1981). "An Introduction Studies in Population, Labour Force and Migration Survey in Pakistan". PIDE Research Report No. 118, Islamabad. 
Kazi to draw some tentative inferences about whether such changes are underway in Karachi.

\section{KARACHI: AN IDEAL SETTING FOR CHANGE?}

Karachi is the major modern centre of Pakistan, it is the heart of commercial, financial and communications activity for the rest of the country. From our survey we find educational attainment to be much higher in Karachi and gender inequality of schooling ratios to be less here (Kazi and Sathar 1988). Whereas 47 percent of boys aged 5-19 are attending school, 45 percent girls are enrolled also. These are much higher ratios as compared with the rest of the country and even when compared to other urban areas. According to a priori expectations it can be predicted that higher schooling ratios must be associated with lower fertility due to the changing calculus of associated value and costs of children. In brief, as more families send their children to school, fewer of them will contribute to household labour and income and their costs will rise thus making fewer children a more economically attractive option. In another study of women's status and fertility it was also concluded that Karachi or major urban areas would contain a concentration of women of higher status, those with higher education and in modern sector employment. Both these factors have been associated with markedly reduced fertility (Sathar 1986). Also in terms of availability of means of fertility control, Karachi is more likely to have the greatest density of available service delivery outlets. So, if there is a latent demand for contraception, there is at least a greater abundance, than in the rest of the country, of supply and advice on contraception for this demand to be met.

In summation, Karachi for these reasons is expected to lead the demographic transition in Pakistan. Given that Karachi comprises almost 10 percent of the total population of Pakistan, its demography in itself is worth studying.

\section{DATA}

Though we draw on the findings of surveys such as the Pakistan Contraceptive Prevalence Survey 1984, the Pakistan Fertility Survey 1975 and the Population, Labour Force Migration Survey 1979, we rely primarily on data collected under the project "Metropolitan Women's Productive and Reproductive Choices". For this study we utilize information from marriage and reproductive histories and contraceptive use information collected for 680 working and 320 non-working women in Karachi. The sample was purposively collected but we feel that the distributions of women across age groups (15-49) and income groups makes them broadly representative of behaviour patterns for Karachi. For details about the survey, readers are referred to a full report of the findings of the project (Kazi and Sathar 1988).

\section{EVIDENCE OF FERTILITY DECLINE}

The first signs of changes in fertility in Karachi were seen in the lower Tota Fertility Rate of women in major urban areas as reported in the Pakistan Contraceptive Prevalence Survey 1984 (Table 1). Previous surveys did not bifurcate the tota fertility rate by major and other urban. However as seen in the table mean parities were not different across major urban and other urban areas. In our survey we found lower fertility in our sample than reported in the PCPS. (Table 2). Women

Table 1

Urban-rural Differentials in Fertility in the PFS, PLM and PCPS

\begin{tabular}{lccc}
\hline & Major Urban & Other Urban & Rural \\
\hline & Total Fertility Rate & \\
PFS (1975) & $6.2^{1}$ & - & 6.4 \\
PLM (1979) & $6.2^{1}$ & - & 6.6 \\
PCPS (1984) & 5.5 & 6.1 & 6.2 \\
& Mean Children Ever Born & \\
PFS (1975) & $4.4^{1}$ & - & 4.0 \\
PLM (1979) & $4.4^{1}$ & - & 3.9 \\
PCPS (1984) & 4.4 & 4.4 & 4.2 \\
\hline
\end{tabular}

Source: Government of Pakistan [(1986); I. Alam (1984); Alam et al. (1983); Z. Sathar (1979)] 'Includes both major urban and rural areas.

${ }^{2}$ Based on births in the last 12 months in the household and not to currently married women

${ }^{3}$ Based on children ever born to currently married women not ever-married women.

\section{Table 2}

Mean Number of Children Ever Born by Five Year Age and Duration of Marriage Groups for Currently Married Women

\begin{tabular}{lrrrrrrrr}
\hline $\begin{array}{l}\text { Age of } \\
\text { Mother }\end{array}$ & $15-19$ & $20-24$ & $25-29$ & $30-34$ & $35-39$ & $40-44$ & $45+$ & All \\
\hline & .50 & 1.55 & 2.57 & 3.72 & 4.68 & 4.77 & 4.88 & 3.83 \\
\hline $\begin{array}{l}\text { Duration of } \\
\text { Marriage }\end{array}$ & $0-4$ & $5-9$ & $10-14$ & $15-19$ & $20-24$ & $25+$ & All \\
\hline & .86 & 2.38 & 4.08 & 4.56 & 5.42 & 5.51 & 3.83 \\
\hline
\end{tabular}


in Karachi seem to have lower fertility by broad age groups than women in major urban areas. It must be remembered that our data also refer to 1987 , three years later after the PCPS and the findings present some tentative evidence of fertility decline in the very recent past.

What factors are attributable to the fertility decline or for the lower levels of fertility in Karachi? If seen historically, through data collected on a special study of the people of Karachi done in the 1960 's, fertility levels in the city were not particularly different from the rest of the country. The total fertility rate was around 6.5 per 1000 . women (Hashmi et al. 1964). So what we see must then be a recent trend. One of the major factors affecting fertility downwards must be the rising age at marriage of females, which registered the highest rise for major urban areas. In another study using the Population, Labour Force and Migration Survey we found that the singulate mean age at marriage of women had risen from 18.5 years in the 1961 Census to 21.5 years in the 1981 Census. This rise of 3 years was the largest for that period as compared to Lahore, other urban areas and rural areas (Sathar and Kiani 1986)

The higher age at marriage amongst females is expected to have a lowering effect on total fertility rates and on the crude birth rate unless of course it is compensated by rises in marital fertility. We will look first at whether a later age at marriage is necessarily associated with lower marital fertility as this was not found to be the case in the PFS and the PLM [Alam (1984) and Alam et al. (1983)]. In the case of Karachi, we do find fertility to be related inversely to age at marriage (except for the lowest ages at marriage) thus rising age at female marriage is expected (all else being equal) to lead to reduced fertility (Table 3 ).

Table 3

Mean Number of Children Ever Born by Age at Marriage and Duration of Marriage Groups

\begin{tabular}{lrrrrrr}
\hline $\begin{array}{c}\text { Age at } \\
\text { Marriage }\end{array}$ & \multicolumn{5}{c}{ Duration of Marriage } \\
\cline { 2 - 7 } & $0-4$ & $5-9$ & $10-14$ & $15-19$ & $20+$ & All \\
\hline $15-18$ & 1.0 & 2.9 & 4.1 & 4.5 & 5.2 & 4.2 \\
$19-21$ & .9 & 2.4 & 3.4 & 4.7 & 4.2 & 3.8 \\
$22-25$ & .8 & 2.2 & 3.7 & 3.6 & 4.1 & 2.8 \\
$26+$ & .8 & 1.7 & 3.5 & 3.5 & $(4.8)$ & 1.9 \\
\hline
\end{tabular}

( ) Based on less than 10 cases.
As pointed out earlier, we expect that a change in marital fertility has occurred in the recent past and would not be the outcome of two decades of changing marriage patterns. In looking at births in the last five years and the five-year period before that we find some evidence that marital fertility has declined in the successive five-year period - average births to women seem to have declined (Table 4). However, we have to be wary of data artifacts often found in birth history reporting which show spurious fertility declines (Retherford et al. 1987). At face value the findings do seem to reflect a lowering of marital fertility over the two periods, particularly at later ages. At younger ages fertility may have risen slightly.

The only reason for expecting marital fertility to rise would be the declining trend in breast-feeding patterns which has been recorded for Pakistan over the period 1975-76 (Khan 1985). The duration of breast-feeding in urban areas has been registered to be lower than in rural areas and, we expect, would be the shortest in major urban areas. Whether or not this shortening of the period of breast-feeding actually alters patterns of birth-spacing is most relevant from the point of view of fertility levels and evidence of changes in birth-spacing patterns across the PLM and PFS does not show any major shifts (Kiani 1988).

The data from Karachi show that the median period of breast-feeding falls

Table 4

Mean Number of Births of Currently Married Women by Age in 0-4 and 5-9 Years Preceding Survey

\begin{tabular}{|c|c|c|c|c|c|c|c|c|}
\hline \multicolumn{9}{|c|}{ Current Age } \\
\hline & $\mathrm{TMFR}^{1}$ & $15-19$ & $20-24$ & $25-29$ & $30-34$ & $35-39$ & $40-44$ & $45+$ \\
\hline \multicolumn{9}{|l|}{$\begin{array}{l}\text { Mean Number } \\
\text { of Births }\end{array}$} \\
\hline $0-4$ Years* & 5.83 & .58 & 1.25 & 1.34 & 1.17 & .88 & .54 & .07 \\
\hline 5-9 Years & 6.15 & .37 & 1.20 & 1.61 & 1.49 & 1.15 & .34 & - \\
\hline \multicolumn{9}{|l|}{$\begin{array}{l}\text { Number of } \\
\text { Women }\end{array}$} \\
\hline $0-4$ Years & & 12 & 51 & 189 & 173 & 177 & 132 & 137 \\
\hline 5-9 Years & & 51 & 89 & 173 & 177 & 132 & 137 & - \\
\hline
\end{tabular}

*These averages include January-April 1987 and therefore cover a longer period than the $5-9$ years prior to survey.

'This is the sum of mean births to currently married women and strictly speaking not the TMFR 
at 11 months and the proportion of children who are not breast-fed at all are a notable 16 percent. Since this is less than the estimated median length of breastfeeding of about 15 months from the whole country for 1979 we expect that this shortening of breast-feeding is having an increasing effect on marital fertility as it reduces the period of post-partum amenorrhea after birth.

However, the positive effect of reduced breast-feeding on fertility is usually offset in societies undergoing transition by increased contraceptive use. This is the case in Karachi, as current use of contraceptives amongst ever-married women is about 40 percent which is higher than national averages of about 10 percent.

As an exercise to disentangle possible effects of breast-feeding and contraceptive use on marital fertility we compare the application of the Bongaarts model to major urban areas from the PCPS and to our own Karachi data. Readers need to be forewarned that this exercise, presented in Table 5, contains tentative results particularly those pertaining to breast-feeding and is useful only as a tool to see that contraceptive use in Karachi is most probably high enough to counteract lower breast-feeding and in sum may beginning to lead to lower fertility.

Table 5

Application of the Bongaarts Model ${ }^{2}$ to Major Urban Areas (PCPS and Karachi Women)

\begin{tabular}{ccc}
\hline & $\begin{array}{c}\text { Major } \\
\text { Urban (PCPS) }\end{array}$ & $\begin{array}{c}\text { Karachi } \\
\text { Survey }\end{array}$ \\
\hline Length of Lactational Infecundability & 7.2 & 5.9 \\
$C_{i}$ & .778 & .821 \\
Level of Contraceptive Use & .25 & .40 \\
$C_{c}$ & .773 & .635 \\
$C_{m}$ & .628 & - \\
Total Fecundity $(14.5) X C_{i}$ & 11.28 & 11.90 \\
If $X C_{i} X C_{c}=$ Estimated TMFR & 8.72 & 7.56 \\
If $X C_{i} X C_{c} X\left(C_{m}=.628\right)^{1}=$ Estimated TMFR & 5.47 & 4.75 \\
\hline
\end{tabular}

'As computed for PCPS Major urban areas and assumed to be the same for Karachi women. ${ }^{2}$ For details of the Bongaarts Model refer to Bongaarts and Potter (1983).
According to this exercise the most critical variable in reducing fertility levels in Karachi, apart of course from the pattern of later marriages which affects TFR and TMFR (according to Table 4) is notably high levels of contraceptive use recorded in our survey. As pointed out earlier Karachi, more than any other location in Pakistan, contains better delivery of population planning services and advice and it is worth pointing out some of the patterns of use which may help us to extrapolate for the future in other settings.

In Table 6 we see the usual positive association between contraceptive use and family size but more interesting is the finding that contraceptive use figures are almost 40 percent for ever-married women even when they have one living son or one living daughter. After women have two living sons or two living daughters; use levels are in the region of 50 percent (use levels are slightly higher when the number of living sons is one or two as compared to the equivalent number of living daughters). Thus women in Karachi, at least from an initial look at this data, seem to be aiming for two children of each gender at most. This is supported by the analogous finding that even if women have no living daughters or no living sons, almost two-thirds say they do not want more children or at least to space their children.

It is interesting however, to note that even though contraceptive use rates are

Table 6

Proportions using Contraception and Proportions Wanting No More Children by Number of Living Sons and Daughters

\begin{tabular}{lccccccc}
\hline & \multicolumn{6}{c}{ Number of Living Daughters } \\
\cline { 2 - 7 } & 0 & 1 & 2 & 3 & 4 & $5+$ \\
\hline $\begin{array}{c}\text { Proportion Currently } \\
\quad \text { Using Contraception } \\
\begin{array}{c}\text { Proportion Wanting } \\
\text { No More Children }\end{array}\end{array}$ & 18.3 & 38.3 & 49.2 & 55.7 & 49.3 & 51.9 \\
& 66.1 & 70.8 & 81.9 & 87.0 & 89.6 & 90.7 \\
$\begin{array}{c}\text { Proportion Currently } \\
\text { Using Contraception }\end{array}$ & 16.7 & 42.2 & 52.3 & 49.0 & 45.0 & 59.2 \\
$\begin{array}{c}\text { Proportion Wanting } \\
\text { No More Children }\end{array}$ & 60.4 & 70.0 & 83.9 & 94.0 & 95.0 & 95.0 \\
\hline
\end{tabular}


Table 7

Additional Children Desired by the Number of Mean Number and Sex Ratios of Living Sons and Daughters

Mean Number of Additional Children Desired

\begin{tabular}{crrrrrr}
\hline \multirow{2}{*}{$\begin{array}{c}\text { Number of Living } \\
\text { Daughters }\end{array}$} & 0 & 1 & 2 & 3 & 4 & $5+$ \\
\cline { 2 - 7 } & 3.41 & 1.83 & 1.07 & .35 & .63 & .86 \\
\hline 0 & 2.82 & 1.01 & .66 & .14 & .30 & - \\
1 & 1.55 & .53 & .26 & .06 & .40 & .20 \\
2 & .40 & .45 & .27 & .25 & - & - \\
3 & .91 & .56 & .21 & - & - & - \\
4 & .38 & - & .18 & - & - & - \\
\hline
\end{tabular}

Sex Ratios (Number of Additional Sons Desired/ Number of Additional Daughters Desired) of Additional Children Desired

\begin{tabular}{ccccccc}
\hline \multirow{2}{*}{$\begin{array}{c}\text { Number of Living } \\
\text { Daughters }\end{array}$} & 0 & 1 & 2 & 3 & 4 & $5+$ \\
\cline { 2 - 7 } & 1.33 & .95 & .55 & .67 & - & .51 \\
\hline 0 & 2.00 & 1.59 & 1.54 & .56 & .76 & + \\
2 & 8.11 & 3.08 & 1.89 & - & 1.67 & 1.0 \\
3 & - & - & 3.38 & 2.08 & - & - \\
4 & - & - & - & - & - & - \\
$5+$ & $-*$ & $-*$ & $-*$ & $-*$ & $-*$ & $-*$ \\
\hline
\end{tabular}

+Only demand for boys.

*Only demand for girls. high in Karachi, as compared to the rest of Pakistan, there still seems to be a gap between those who do not say they want more children but yet do not use contraceptive methods (very roughly speaking the difference between the proportion wanting no more children and those currently using contraception). This is to say that there seems to be considerable untapped potential to motivate contraceptive use, particularly for those wanting to space births and those who are unsure of wanting additional children.

In Pakistan, even where overall contraceptive use figures are low, there is some evidence to suggest that gender of children and gender composition of families does influence reproductive behaviour (Casterline 1984). We look lastly at this behaviour of son preference and its degree of prevalence in the Karachi setting since it has been argued to be a feature which adds an upward pressure to family size. As can be seen in Table 7 , the desire for at least one son persists even when mothers have up to 4 daughters and no sons and for one daughter even when there are up to 5 sons and no daughters. However, in general after families have three or more living sons their desire for additional children certainly wants much more than in the case of three daughters or more.

\section{CONCLUSIONS}

In conclusion there does seem to be concrete evidence that fertility in Karachi may be falling in the recent past and, certainly, fertility levels are lower than in the rest of the country. These fertility levels are largely an outcome of the higher age at marriage of females and higher contraceptive use as compared to other areas of Pakistan. This is despite the shorter length of breast-feeding and smaller proportions who breast-feed their children. However the motivation for smaller families may be emerging as an important contributing factor given the higher schooling ratios and the lower infant mortality rates found in the city.

\section{REFERENCES}

Alam, I., and J. Casterline (1983). "Socio-Economic Differentials in Recent Fertility" World Fertility Survey. Comparative Studies. No. 33.

Alam, I. (1984). "Fertility Levels and Trends". In I. Alam and B. Dineson (eds.), Fertility in Pakistan: A Review of Findings from the Pakistan Fertility Survey. Voorburg: International Statistical Institute.

Alam, I., et al. (1983). "Fertility Levels, Trends and Differentials in Pakistan: Evidence from the PLM Survey 1979-80". Islamabad: Pakistan Institute of Development Economics. (Studies in Population, Labour Force and Migration Report No. 1)

Bongaarts, J., and R. Potter (1983). Fertility, Biology and Behaviour. London: 
Academic Press.

Casterline, J. (1984). "Fertility Differentials" In I. Alam and B. Dineson (eds.), Fertility in Pakistan: A Review of Findings from the Pakistan Fertility Survey. Voorburg: International Statistical Institute.

Hashmi, S., M. R. Khan and K. Krotki (1964). The People of Karachi. Karachi: Pakistan Institute of Development Economics.

Kazi, S., and Z. Sathar (1988). Productive and Reproductive Choices of Metropolitan Women: Survey Report. Islamabad: Pakistan Institute of Development Economics.

Khan, Z. (1985). "Breast-feeding in Pakistan". Islamabad: Pakistan Institute of Development Economics. (Studies in Population, Labour Force and Migration Report No. 10)

Kiani, F. (1988). "The Dynamics of Birth-Spacing and Marital Fertility in Pakistan, PLM 1979 Survey”. Paper presented at the Fifth Annual General Meeting of the Pakistan Society of Development Economists, January, 1989.

Pakistan, Government of (1986). Pakistan Contraceptive Prevalence Survey. Islamabad: Population Planning Division.

Retherford, R., et al. (1987). "Fertility Trends in Pakistan - The Decline That Was Not". Asian Pacific Population Forum. Vol. 1, No. 2.

Sathar, Z. (1979). "Rural-Urban Fertility Differentials in Pakistan: 1975". Pakistan Development Review. Vol. XXV, No. 4.

Sathar, Z. (1986). "Women's Status and Fertility in Pakistan". Paper presented at Rockefeller Foundation Workshop on Status of Women in Mount Kisco, July 1986, New York.

Sathar, Z., and F. Kiani (1986). "Delayed Marriages in Pakistan". Pakistan Development Review. Vol. XXV, No. 4.

\section{Comments on \\ "Evidence of Fertility Decline in Karachi"}

Mr Chairman I take this opportunity to thank the organizers for inviting me to this meeting of the Society. In fact, I feel honoured to be asked to review papers on some very important issues.

Fertility as we all know is the ability of an individual to conceive or induce conception, the rate is determined by an end measure i.e. births. In this context we are confronted with a two dimensional problem, a situation in which about 10 percent of all married couples are unable to reproduce i.e. infertility. On the other hand is a more serious problem, particularly for developing country like ours, of how to control fertility, high fertility rate has resulted in tremendous growth in our population putting severe pressure on resources, energy, and ultimately affecting health, education and economic status of the populace at large.

Our national surveys reveal that about 75 percent of married couples know about contraceptive methods. However those actually using these methods are not more than 10 percent. This wide gap between knowledge and practice of contraception needs to be narrowed. It requires thorough and concerted efforts to look at the factors affecting the acceptability of contraceptive techniques in the presence of a wide variety of counterforces and to assess the fertility pattern in different population samples with accepted categorization. The paper under review is a good attempt to evaluate various factors contributing to the reported decline in the fertility rate in a given population. I would certainly compliment Dr Zeba Sathar for her efforts.

The paper deals with the fertility rate in the sample chosen from an urban society. I feel that data from 1000 working and non-working women is not a true representative of the behaviour pattern particularly in a society like in Karachi. Before drawing any conclusions one should take certain variables into consideration. One: percentage of working women belonging to different socio-economic groups, their education level, ethnicity etc. It is a common observation that the proportion of working women belonging to the higher socio-economic class is much lower. Two: working women again has to be defined or grouped on the basis of the education level, age and ethnicity which certainly would affect the overall fertility rate.

Coming to the paper, in Table 1 abbreviations are used. I think this is not a good practice. According to accepted convention for presentations, abbreviations are defined when first used in the text. Table 2 the source is not cited. Although we 
assume that the duration of marriage is in years, it should be spelt out. In Table 3 if the number of cases in each group are mentioned it would make the finding more meaningful. In Table 4 abbreviation TMFR is used which has not been defined earlier in the text. The percentage of contraceptive users in Karachi seems to be very high. We would certainly like to know about the source and group of population from which the data have been derived. Furthermore, it would be of interest if these contraceptive use figures are compared with those from other major urban areas/ cities of the country and commented upon.

Finally I come to the conclusions. From the selection of samples which you mention has been done purposedly I felt you would compare the fertility pattern in two groups i.e. working and non-working women and would draw conclusions from that, but after selection of the sample there is no mention of that in the entire presentation. Instead, discussion has focused on aspects like breast-feeding contraceptive use, etc.

I would like to suggest that the authors to make some comment on that aspect and secondly, how would she define a representative sample population.

Arif Ali Zaidi

Aga Khan University,

Karachi 